\title{
Global Abortion And Marketing Challenges For Misoprostol (Cytotec): The Future Of Women's Health
}

Osvaldo Antommattei, Nova Southeastern University, USA Nile M. Khanfar, Nova Southeastern University, USA

Bahaudin G. Mujtaba, Nova Southeastern University, USA

\begin{abstract}
This paper provides an overview of the controversial drug Misoprostol (Cytotec) and its importance for women's health worldwide while presenting global challenges related to abortion. Furthermore, this paper discusses marketing challenges and opportunities that exist in today's global marketplace for this drug. Misoprostol is an approved drug utilized to prevent stomach ulcers caused by non-steroidal anti-inflammatory drugs (NSAID's), but it also has an "off label" use as an abortion pill for which it is being used today. Worldwide implications are vast and Misoprostol presents a future challenge for clinical studies and marketing professionals.
\end{abstract}

Keywords: Misoprostol (Cytotec), abortion, marketing, global challenges, drugs, women's health.

\section{BACKGROUND AND IMPORTANCE OF THE DRUG}

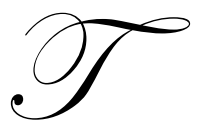

he pharmaceutical company that produces Misoprostol does not encourage its "off label" use as an abortion pill; therefore, they have not marketed the drug for the past several years. However, many countries that do not follow FDA regulations use Misoprostol as an abortion pill. There are worldwide implications for the use of this drug because in many countries it may benefit women who otherwise would have severe complications or even die during an abortion.

In 1988, Misoprostol (Cytotec) was approved and sold by Monsanto Co., a success for Searle Pharmaceutical, now distributed by Pfizer Pharmaceuticals, to prevent stomach ulcers caused by NSAID drugs, such as aspirin, ibuprofen, piroxicam, and naproxen. ${ }^{1}$ This cyto-protective drug acts by replacing prostaglandins in the stomach and also has an "off-label" or unapproved use as an abortion pill. Searle never intended Misoprostol (Cytotec) to be used as an abortion pill, nor has it been approved in Britain or France with or without RU-486. The drug's label has a contraindication in women of childbearing potential. ${ }^{2}$ The controversy of this drug is that since abortion was legalized in 1973, abortion drugs containing a prostaglandin are used to terminate early pregnancies. In Europe, women use Misoprostol (Cytotec) for two days to bring about a complete abortion. Misoprostol (Cytotec) is used in France for this purpose (as an "off- label" drug), but the company that manufactures Misoprostol (Cytotec) never officially intended to seek approval for its use. Nevertheless, France, which has no FDA regulation but is considered one of the top leading countries in pharmaceutical development, requires the selling of Misoprostol (Cytotec) as an abortion drug. ${ }^{3}$

Some pharmaceutical companies are looking for ways to confer scientific literature on "off-label" or unapproved drug use. Accordingly, in other countries many physicians already are permitted to prescribe drugs for unapproved uses. ${ }^{4}$ It should be noted that the FDA regulates the educational value of information when direct-toconsumer advertising is conducted. Misoprostol was never intended for use as an abortion pill in the U.S.; however, it was established by the FDA as a potential risk for its unproven studies on abortion. This is why drugs with FDA approval may be marketed to consumers. Evidence has shown that widespread use of new drugs may be counterproductive in the absence of solid evidence and studies of an advantage over existing conventional alternatives. ${ }^{5}$ Present studies on the use of Misoprostol have been reported, but there is still much research to be 
done before direct-to-consumer marketing can ever take place in the United States. Consequently, a percentage of all drugs are withdrawn from the market for health-related reasons.

\section{LITERATURE REVIEW OF STUDIES}

Since the pharmaceutical industry has looked the other way in U. S. markets in developing and registration of Misoprostol for pregnancy failures, studies have been limited by a small number of subjects. Following are results that demonstrate the efficacy, safety and acceptability of treatment with Misoprostol.

In 2005, a study of $800 \mu \mathrm{g}$ of Misoprostol (Cytotec) was given vaginally to induce early pregnancy failure, with a repeated dose after 48 hours when it was necessary. A population of 652 women participated in this study. Of this population, 491 were assigned to Misoprostol (Cytotec) with complete success and 161 (16\%) were assigned to vacuum aspiration when Misoprostol was not effective in the randomized trial. ${ }^{6}$ In this study the women who participated had inevitable abortions defined as an intrauterine gestational sac of less than $45 \mathrm{~mm}$ with active vaginal bleeding. Participants were excluded if they had anemia, hemodynamic instability, history of clotting disorder or were using anticoagulants. All participants gave their written informed consent and were treated with four $220 \mu \mathrm{g}$ tablets $(800 \mu \mathrm{g})$ of Misoprostol (Cytotec) inserted into the posterior formic through a speculum. For the most part, all women returned after three days (range two to five days) for a second $800 \mu \mathrm{g}$ dose. If the abortion was not completed, then vacuum aspiration was offered. ${ }^{6}$

Results of the study confirmed the majority of patients (84\%) treated with Misoprostol were successful in the treatment for abortion. Success was defined as the absence of the need for vacuum aspiration for any reason within 30 days. There were common side effects reported, such as nausea, vomiting, and abdominal pain. The greater part of the participants, an approximate $83 \%$, stated they would recommend this treatment for their family and friends. More than three-fourths of the participants (78\%) would use Misoprostol again for this treatment. The positive outcome of this study showed that the risk of pelvic infection and hemorrhage was very low and side effects were tolerable. ${ }^{6}$

Other studies conducted with Misoprostol had similar results. A study in India used a lower dose $(400 \mu \mathrm{g}$ vaginal Misoprostol) to induce medical evacuation of early pregnancy failure. Though a smaller study with a population of only 60 patients, it had similar results; over three-fourths (77\%) had a complete abortion. Surprisingly $70 \%$ had completely expelled the fetus with the first dose. The conclusions were that the needs for surgical treatments for alternative abortions are more dangerous than Misoprostol treatment. ${ }^{31}$

Another study conducted in 2005 in the "Clinical Materno Infante of Toluca", Mexico, determined the efficacy of different doses of Misoprostol in an intra-vaginal controlled-release. The maximum controlled dose of $100 \mu \mathrm{g}$ produced more rapid vaginal deliveries in a shorter time. Higher doses did not shorten the time in vaginal delivery. ${ }^{7}$

Acceptance among the medical professionals has been significant. The support in medical literature is significant for the positive results of early abortion and the experiences of medical professionals and health providers. Cultures that support early abortions but have limited funding may influence providers to adopt this new technique. ${ }^{8} \quad$ In Scotland, physicians have utilized regimens that are cost-efficient rather than utilizing hospital operating rooms, which typically involves general anesthesia. The post abortion follow-up visits are crucial to make sure that the abortion was complete and that there are no further complications. ${ }^{8}$

\section{GLOBAL PERSPECTIVE AND RESEARCH OVERVIEW}

According to available data, induced abortions have seen a decline of four million worldwide between 1995 and 2003, coming down from 46 million to approximately 42 million. By 2003, there were 26 abortions per 1,000 women in developed countries in contrast to 29 per 1,000 in developing countries. ${ }^{9}$ A decrease in developing countries is observed rather than in developed countries. A strong market for safe induced abortions worldwide is a need especially in parts of Asia, Latin America and Africa. Complications due to unsafe abortion procedures account for an estimated $13 \%$ of maternal deaths worldwide and it is estimated that millions of women are 
hospitalized due to complicatons. ${ }^{10}$ Cuba and the Russian Federation have the highest abortion rates of $109 \%$ and $104 \%$ percent respectively, indicating that more abortions than births occur annually. ${ }^{11}$ Even though induced abortions have fluctuated from country to country, there is still a great need for legal abortions worldwide. This market should be analyzed for there is a great market for a supplier of prostaglandins together with the abortion pill RU-486 to successfully terminate pregnancy. In many countries, Misoprostol is used for this procedure. To increase its market share, studies should be focused on the effects of this drug. If Misoprostol is utilized, hospitals and community pharmacists would play an important role in collecting reports of adverse drug reactions (ADR's); for this would be the basis of post-marketing surveillance of the drug. Since millions of women are hospitalized due to complications of abortions, hospital pharmacists may serve as a key instrument in the pharmacovigilance of this "off-label" drug. Today the pharmacist also frequently acts as a consultant on pharmacotherapy for both physicians and patients even though the fundamental role is to ensure the safety of medicines. ${ }^{12}$ Hospital pharmacists are directly involved in patient care and can document and monitor this "off-label" medicine. On a worldwide scope, pharmacists can be instrumental in "off-label" drugs for the pharmacokinetics, pharocodynamic and interactions of drugs that can determine the overall effects.

Table 1 - Maternal Mortality (WHO, 2000)

\begin{tabular}{|c|c|c|c|}
\hline \multicolumn{4}{|c|}{ Estimates of Maternal Mortality, 2000.* } \\
\hline Region & $\begin{array}{l}\text { Maternal Mortality } \\
\text { Ratio } \\
\text { no. of deaths/ } \\
100,000 \text { live births }\end{array}$ & $\begin{array}{c}\text { Maternal } \\
\text { Deaths } \\
\text { no. }\end{array}$ & $\begin{array}{l}\text { Lifetime Risk of } \\
\text { Maternal Death }\end{array}$ \\
\hline World total & 400 & 529,000 & 1 in 74 \\
\hline Developed regions & 20 & 2,500 & 1 in 2800 \\
\hline Europe & 24 & 1,700 & 1 in 2400 \\
\hline United States & 17 & 660 & 1 in 2500 \\
\hline Developing regions & 440 & 527,000 & 1 in 61 \\
\hline Africa & 830 & 251,000 & 1 in 20 \\
\hline Northern Africa & 130 & 4,600 & 1 in 210 \\
\hline Sub-Saharan Africa & 920 & 247,000 & 1 in 16 \\
\hline Asia & 330 & 253,000 & 1 in 94 \\
\hline East Asia & 55 & 11,000 & 1 in 840 \\
\hline South Central Asia & 520 & 207,000 & 1 in 46 \\
\hline Southeast Asia & 210 & 25,000 & 1 in 140 \\
\hline West Asia & 190 & 9,800 & 1 in 120 \\
\hline Latin America and the Caribbean & 190 & 22,000 & 1 in 160 \\
\hline Oceania & 240 & 530 & 1 in 83 \\
\hline
\end{tabular}

* Data are from the World Health Organization (WHO). ${ }^{2}$ According to the WHO, the maternal mortality ratio is a measure of the risk of death after a woman has become pregnant, and the lifetime risk of maternal death takes into account the probabilities of becoming pregnant and of dying as a result of pregnancy cumulated over a woman's reproductive years. Developed regions include, in addition to Europe and the United States, Canada, Japan, Australia, and New Zealand, which are excluded from the regional totals.

For the past 20 years, improving maternal health has been an issue on the global agenda. It is estimated that 500,000 or more women die each year due to complications from pregnancy and childbirths. ${ }^{32}$ This is more evident in developing regions like Africa and Asia, unlike developed regions like Europe and the U.S. as clearly indicated in Table 1.

Further research needs to be done on the medical management of Misoprostol for early pregnancy failures. The lowest effective dose of Misoprostol for each individual condition is not yet clear since there are different categories of pregnancy loss. Doses of the drug may vary for different categories of patients and their different conditions. The safety, efficiency and acceptability of this treatment should be studied further. The statistical 
analysis reported in the New England Journal of Medicine of August 25, 2005, that pregnancy failure treated with $800 \mathrm{mg}$ of Misoprostol vaginally was a safe approach with $84 \%$ high success rate. Future studies conclude the same results. Marketing of Misoprostol may be studied for market penetration to countries where the "off-label" drug is presently utilized and FDA regulations are none existent. Indirect marketing may then be used not only to focus on Misoprostol as an ulcer drug, but by indicating the "off label" effects. One would be indirectly marketing other possible uses without breaking any laws. Marketing efforts with worldwide distributors are important due to worldwide demand and saving the lives of less fortunate women. The uterotonic and cervical ripening actions it has on women and the possibility of treating or preventing post-partum hemorrhage would also influence the market. Pharmacokinetics, due to different routes of administration, cause different side effects and acid peaks which slowly decline. These side effects are of essence for early termination. Due to lack of studies, there is no specific indication on the amount of drug that should be administered.

\section{PHARMACEUTICAL MARKETS}

Pharmaceutical companies need to cover many different markets to diminish the high costs of researching and developing of drugs. When a drug has "off-label" uses in different countries, it creates a great opportunity for a new product, as long as the legal and government restrictions don't conflict with the drug's use and expected drug results. Existing drugs compete with new drugs, which may reduce the probability of expected entry acceptance. Demographics provide a rough measurement of demand and market size, and a company's number of drugs measures the expertise in that market. ${ }^{14}$ Canada, Mexico, the Netherlands, and Sweden enact price controls during sample periods as reactions to perceived high profits to be earned by pharmaceutical companies. ${ }^{14}$

Market regulatory barriers of price regulation are fixed and variable costs must be a concern before introducing drugs to the market. Competition of generics and other substitute drugs are available in markets. All this diminishes market advertising, but not entirely withdraws it. There is a risk when first introducing new drugs to the market, but it soon diminishes. Those countries that regulate price controls by governments should not discourage the introduction of a drug since volume of sales and patient satisfaction will ultimately produce a positive return. In pharmaceutical markets, not only is the cost/benefit relation a concern, but also the worldwide benefit of a drug is of great importance. Misoprostol (Cytotec) is considered a mature product (by its company); therefore, for the past couple of years, it has not been marketed for use as ulcer and gastric treatment. Although its "off-label" use as an effective abortion pill is utilized worldwide, the pharmaceutical company will not market this drug for fear of repercussion of anti-abortion groups and boycotts. Distributors are utilized for this drug, which may suggest the avoidance of price-controlled markets that enable high price for its therapeutic value. ${ }^{14}$ At the mature stage of a drug, the product sales growth slows down even though, at this point, it lasts longer. Marketing management of a mature drug is important because overcapacity leads to greater competition, especially when a drug competes with generics. ${ }^{15}$ At this stage, it is prudent to increase the budget of Research and Development to find different versions of the drug, especially when women around the world can benefit from this product. The use of Cytotec is evolving to meet patient's needs.

\section{ABORTION AND WORLD WIDE MARKETS}

When analyzing the worldwide marketing environment, one must consider political/legal, socio/cultural and demographic factors, together with the specific need to increase safety in abortions today. Even though induced abortions have declined from approximately 46 million to 42 million, about one in five pregnancies worldwide ends in abortion. ${ }^{16}$ This is demonstrated more in developed countries where more contraceptives and information is available and where abortions are legal and safe. In developed countries, such as eastern Europe, there are more abortions than births; however, developing countries, such as Africa, also have experienced an increase in induced abortions. ${ }^{16}$ In Asia and Latin America, a slow decline is reported, probably due to political and legal implications. An example of this is the country of El Salvador where abortion is a serious felony for everyone involved. Women may serve up to 30 years in prison and health providers may also serve 6 to 12 years. ${ }^{17}$ In Asia, most abortions occur due to the concentrated population. Socio-cultural influences on nations also play a big role. In South America, a very Catholic influence affects the political and legal system. There is an emphasis to restrict induced abortion laws in Latin America in the past years. Only in Cuba and a few other Caribbean nations is abortion legal and safe. An example of this is Uruguay, where the Senate was three votes shy of legalizing abortion, and Argentina's Congress, 
in some instances, is considering bills to legalize abortion. ${ }^{18}$ Even though Latin America has strict abortion laws, it is developing a high abortion rate in comparison to other nations. A high mortality rate is demonstrated in these areas because there are strict laws which force the abortions to be performed clandestinely. One of the largest Catholic countries, Brazil, is pushing for new regulations that permit rape victims to get an abortion without police or legal requirements. ${ }^{18}$

Latin Americans do not fully support the legalization of abortions, but many believe abortion should be permitted to save a woman's life if she has been raped or if the fetus will not survive. ${ }^{18}$ In Brazil, abortion is legal in cases of rape or to save the life of the woman.

It is estimated that 100,000 women in the Philippines have complications due to induced abortions and are therefore hospitalized. Many of these women, when faced with the legal constraints and socio-cultural issue in which the country considers abortion a criminal act, must resort to unsafe and clandestine abortions along with the negative connotation. ${ }^{19}$ A nation's socio-cultural influences are the strongest, but one must focus on the healthrelated issues for females as a priority. Worldwide attitudes are slowly changing toward women having successful family size goals and good reproductive health. It may take years, but the shift to focus on women in developing countries is slowly growing as those in developed countries or nations that don't have negative political/legal and socio-cultural connotations of induced abortions. As this happens, potential market for Misoprostol will increase and the demand for a safe drug to induce abortions will grow. Changes in the environment will increase future demands that will positively affect the global marketplace.

The globalization of the world's economy and the need for safe and effective abortions are great opportunities for Misoprostol. Eastern countries, China, and Latin America are future markets. The pharmaceutical manufacturer drug of Misoprostol (Cytotec) should continue to expand its marketing program to foreign countries, focusing primarily on nations with political stability, and should slowly increase marketing literature of studies to health providers where negative attitudes exist towards safe abortions.

\section{GLOBAL MARKETING: ANALYSIS AND DISCUSSION}

Induced abortion and anti-abortion issues are volatile and create great controversies for pharmaceutical companies, thus the reason why many want to avoid such topics for personal or political reasons. The analysis of expected profit versus the hassles of boycott by anti-abortionists and liabilities is of great concern. Still, times are changing and Misoprostol (Cytotec) represents a great future opportunity. The increasing demand for safe induced abortions is a benefit that adds to consumer satisfaction. The marketing offer of Misoprostol (Cytotec) to women worldwide, especially in nations where abortion is legal, together with governments and organizations, will provide a stable market. Then a marketing management of targeting future markets can continue on with a selective segmentation. The drug production concept of "Misoprostol (Cytotec), a safe induced abortion drug," can be implemented together with more affordability than medical interventions as a great alternative. Even though there is a generic version of the drug marketing of Misoprostol (Cytotec), this should increase the selling concept. Misoprostol (Cytotec) will have to compete with generics, just like brand name pain killers and other over-thecounter drugs compete with generics. Considerations of brand recognitions tend to influence the buyer, thus assuming the quality is greater than that of it's competing generics. Not only is the target market women who ultimately use the drug, but the physicians that prescribe it. By focusing on continuously educating the physicians and health providers, one creates loyalty and retention of the drug. Market penetration of Latin America may start in Mexico where a study was done in 2005 in which the Clinical Materno Infante of Toluca had positive results. Education and clinical studies seem to be the key to developing markets starting with health care providers and women political rights supporters. This will create a relationship of value and more confidence in the drug usage. A managed worldwide marketing effort, commencing with the countries of France, Cuba, and the Russian Federation, will create a bridge to satisfy the need in Asia and Africa. After strengthening existing markets there, an intense educational effort may be implemented where the need is greatest. To measure the results, the control may be in the hospitals and/or clinics to continuously evaluate the results of the drug. Pharmacists may play a key role in monitoring and administrating the drug to health care providers, evaluating the response, and playing an active part if any corrective action is needed for completion of a successful induced abortion. The main goal is the safety and well-being of women. The threat of governments that make regulations against women rights should also be a 
concern. An action program to implement the availability of Misoprostol (Cytotec) should and can be an option, especially when the life of a woman is at stake. Marketing control in hostile environments may present a challenge, for instance in China where millions of abortions take place annually, as legal restrictions do not affect its incidence and the Chinese will not be targeted by anti-abortionists under their laws. Cambodia can be a gateway to all Asian nations since in the past ten years, they have liberalized their laws concerning safe abortions.

\section{LIFE-CYCLE OF THE DRUG}

When a drug reaches the maturity stage, usually the product's growth rate slows down, even though this stage is a longer one. Cytotec has stable distribution channels due its "off-label" use. The growth of sales is relevant to demand by growth of population and replacement demand. Cytotec was intended for NSAID-induced ulcers; today substitute drugs have reduced the product's use for this purpose. While there is the overcapacity of competitors in some countries, marketing personnel must ignore the low success rate of the intended product and must be concerned with the new "off-label" use of this drug. Worldwide successful research, where abortions are legal and necessary to save women's lives, is the new market segment. Maintaining the company's investment and production level until the uncertainties of the product are resolved is prudent. ${ }^{20}$

\section{MANAGEMENT IMPLICATIONS}

A relationship marketing strategy that focuses on keeping and improving customers is one that assumes loyalty and an on-going relationship in search of greater value. ${ }^{22}$ Misoprostol (Cytotec) has had a long-term relationship with the pharmaceutical market, which is why the price is typically low. Since there is no advertising nor promotion, research for new and more reliable ways to improve the product's safety for its "off-label" use should be a consideration. Need recognition and research information affect the consumer decision process of evaluating all the alternatives available to them. Beliefs and expectations, along with attitudes and intentions, influence the actual behavior of consumers. Ultimately, product quality, situational factors, and personal characteristics will all be linked toward customer satisfaction and the perceived value of treatments. Patient feedback is the essential key to prolong the maturity stage of a product.

Demographic variables and psychographic concerns must also play a key role for every country has its own segmentated behavior influenced by cultural, religious and political concerns. The ultimate goal of saving women worldwide must be the priority. Research pharmacists must continue to study the pharmacological aspects, thus achieving a drug that is superior to its predecessors. Diffusion of information is key for scholars to research and find solutions for situations that may arise.

\section{SUMMARY}

Misoprostol (Cytotec) presents a future challenge to pharmaceutical companies for marketing and supplying the worldwide need for induced abortions. This drug provides a safe, effective and affordable way in which abortion could and should be approached. Clinical research supports the advantages of Misoprostol as an abortion drug and the acceptability of the treatment. It is the role of modern pharmacy and its branches, such as Pharmacodynamics and Pharmacokinetics research, which could provide the ideal results to confirm the clinical studies.

The following course of action should be considered: those countries where Misoprostol is approved for ob/gyn indications could serve as a marketing launch point to countries where the drug is approved, but have no indication for the approval of abortion. After these locations are marketed, then those countries where the drug is not approved may follow. Times are changing rapidly, and so is the pharmaceutical industry. It is just a matter of time until Misoprostol is approved worldwide for women in need of abortion.

\section{AUTHOR INFORMATION}

Osvaldo Antommattei is currently completing his professional doctorate degree in Pharmacy (Pharm.D.), at the Nova Southeastern University's College of Pharmacy, at their Puerto Rico campus. Currently, he resides in Ponce, 
Puerto Rico, and wishes to serve his community upon the completion of his doctorate degree. His research interest includes topics in the fields of healthcare ethics, pharmacy and general healthcare.

Nile M. Khanfar, Ph.D., received a Doctor of Philosophy in Pharmacy Administration from the University of Louisiana at Monroe. He is currently an assistant professor at Nova Southeastern University College of Pharmacy in West Palm Beach campus. Dr. Khanfar has presented papers at national and international Business and Pharmacy conferences. His research interest includes topics in the fields of marketing, management and healthcare. His work has been published in several peer-reviewed business and pharmacy journals.

Bahaudin G. Mujtaba, D.B.A., is currently a Department Chair and an Associate Professor of Management and Human Resources Management. Bahaudin was given the prestigious annual "Faculty of the Year Award" for the 2005 Academic Year at Nova Southeastern University's H. Wayne Huizenga School of Business and Entrepreneurship. Bahaudin has served as manager, trainer, and management development specialist in the corporate world as well as a director, department chair and faculty member in academia. His areas of research are management, leadership, customer service, training, diversity management, and cross-cultural management.

\section{CITATIONS / REFERENCES}

1"Monsanto Unit Is Cleared to Sell Ulcer Drug for Arthritis Patients," The Wall Street Journal (Eastern Edition), New York, N.Y., Dec 28, 1998.

${ }^{2}$ Charles L. Frye, "Letters to the Editor: Searle Against Use of Its Drug in Abortion," The Wall Street Journal (Eastern Edition), New York, N.Y., Mar 19, 1993,

${ }^{3}$ Elyse Tanouye and Rose Gutfeld, "Health: U.S. Companies Seek to Market Abortion Pill," The Wall Street Journal, (Eastern Edition), New York, N.Y., Apr 26, 1993,

${ }^{4}$ Elyse Tanouye, "Drug makers seek relaxed restrictions on marketing," The Wall Street Journal, (Eastern Edition), New York, N.Y., Aug 31, 1995,

${ }^{5}$ Joel Lexchips and Barbara Mintzes, "Direct to Consumer Advertising of Prescription Drugs:The Evidence Says No," Journal of Public Policy and Marketing, vol 21-2, Fall 2002,

${ }^{6}$ Jun Zhang, Jerry M. Gilles, Kurt Barnhart, Mitchell D. Creinin, Carolyn Westhoff, and Margaret M. Frederick, for the National Institute of Child Health and Human Development (NICHD) Management of Early Pregnancy Failure Trial, "A Comparison of Medical Management with Misoprostol and Surgical Management for Earl Pregnancy Failure", The New England Journal of Medicine, Vol. 353, No.8, Aug 25, 2005.

${ }^{7}$ Castañeda CS, Izquierdo Puente JC, Leon Ochoa RA, Plasse TF, Powers BL, Rayburn WF, "Misoprostol dose selection in a controlled-release vaginal insert for induction of labor in nulliparous women." American Journal of Obstetrics and Gynecology, Sep 2005, 193(3Pt2):

${ }^{8}$ Rachael K. Jones and Stanley K. Henshaw, "Mifepristone for Early Medical Abortion: Experiences in France, Great Britain and Sweden" Perspective on Sexual \& Reproductive Health, vol.34, Issue \#3, May/June 2002

${ }^{9}$ Sedgh G, Henshaw S, Singh S, Ahman E, Shah IH, "Induced abortion: rates and trends worldwide", Lancet, 2007:370: 1338-45, quoted in "Facts on Induced Abortion Worldwide", Guttmacher Institute, October, 2007

${ }^{10}$ World Health Organization (WHO), "Unsafe abortion: global and regional estimates of incidence of unsafe abortion and associated mortality in 2003, Geneva", WHO, 2007. In Press, quoted in "Facts on Induced Abortion Worldwide", Guttmacher Institute, October, 2007

${ }^{11}$ Gilda Sedgh, Stanley K. Henshaw, Susheela Singh, Akinrinola Bankole and Joanna Drescher, "Legal Abortion Worldwide: Incidence ad Recent Trends", International Family Planning Perspective, Vol 33, Issue 3, Sept 2007

${ }^{12}$ A.C. van Grootheest, M.D., Ph.D., L.T.W. de Jong-van den Berg, Pharm.D., Ph.D. "The role of hospital and community pharmacists in pharmacovigilance", Research in Social and Administrative Pharmacy, 1(2005),

${ }^{13}$ Joel Lexchin and Barbara Mintzes, "Direct-to-Consumer Advertising of Prescription Drugs; The Evidence Says No", Journal of Public Policy \& Marketing, Vol.21(2) Fall 2002,

${ }^{14}$ Margaret K. Kyle, "Entry in Pharmaceutical Markets", Graduate School of Industrial Administration, Carnegie Mellon University, Dec 2, 2002, mkkyle@cmu.edu.

${ }^{15}$ Philip Kotler, Gary Armstrong, Principal of Marketing, $11^{\text {th }}$ edition Pearson Education Inc., Upper Saddle River, New Jersey 2006 
${ }^{16}$ Guttmacher Institute, "Facts on Induced Abortion Worldwide", In Brief, Oct 2007 p.1

${ }^{17}$ Jack Hitt, "Pro Life Nation”, New York Time Magazine, April 9, 2006

${ }^{18}$ Juan Forero, Monica Trujuillo,"Push to Loosen Abortion Laws In Latin America", New York Times, Dec 3, 2005,

${ }^{19}$ Guttmacher Institute,'Improving Reproductive Health in The Philippines", Research in Brief, 2003 series. No.1,

${ }^{20}$ Philip Kotler, Marketing Management Analysis, Planning, Implementing, \& Control, Prentice Hall, Inc., Englewood Cliffs, New Jersey, 1991

${ }^{21}$ Philip Kotler, Gary Armstrong, Principles of Marketing, Pearson Education, Inc., Upper Saddle River, New Jersey, 2006

${ }^{22}$ David A. Holdford, Marketing for Pharmacists, American Pharmaceutical Association, 2215 Constitution Ave, N.W. Washington, DC, 2003

${ }^{23}$ The Alan Guttmacher Institute, "An Overview of Clandestine Abortion in Latin America," Issues in Brief, December 1996

${ }^{24}$ The Allan Guttmacher Institute, "Reducing Unintended Pregnancy And Unsafe Abortion In Uganda," Research In Brief, series. No.1, December 2005

${ }^{25}$ Marsden Wagner, MD, MSPH, "Misoprostol (Cytotec) for Labor Induction: A Cautionary Tale," Midwifery Today, Issue. No. 49, Spring 1999

${ }^{26}$ Marsden Wagner, MD, MS, “Cytotec Induction and Off-Label Use, Midwifery Today, Issue 67, Fall 2003

${ }^{27}$ ClinicalTrials.gov, A service of the National Institutes of Health, " Safety/Efficacy Study Comparing the Misoprostol Vaginal Insert to Cervidil for Cervical Ripening and Induction of Labor”, Inf. Provided by: Cytokine PharmaSciences., Identifier : \# NCT00308711

${ }^{28}$ Lawrence B. Finer and Stanley K. Henshaw, "Estimates of U.S. Abortion Incidence, 2001-2003”, Guttmacher Institute, August 3, 2006

${ }^{29}$ Health Technology Assessment Report, “ Misoprostol in Pregnancy.”, Medical Development Division, Ministry of Health Malaysia; MOH/PAK/93.05(TR)

${ }^{30}$ Timothy F. Bresnahan, Robert J. Gordon, The Economics of New Goods, National Bureau of Economic Research, The University of Chicago Press, Chicago 1997

${ }^{31}$ Thomas Betsy, Habeebullahs; "Vaginal Misoprostol for medical Evacuation of Early Pregnancy Failure", The journal of obstetrics and Gynecology of India, vol. 54, No. 4 July/Aug 2004

${ }^{32}$ Allan RosenfieldMD., Caroline J. Min M.P.H., Lynn P. Freedman, J.D. M.P.H., " Making Motherhood safe in Developing Countries", The New England Journal Medicine; April 5, 2007

${ }^{32}$ Allan RosenfieldMD., Caroline J. Min M.P.H., Lynn P. Freedman, J.D. M.P.H., “ Making Motherhood safe in Developing Countries”, The New England Journal Medicine;_April 5, 2007 pg 1396 